If We Charge Them, Will They Come?

\section{Fostering Positive}

Relationships

with Students by

Remaining Fine-Free

\section{Emma Wood and Jessica Almeida}

Emma Wood and Jessica Almeida both serve as Assistant Librarian for Public Services at the UMass Law Library, University of Massachusetts Dartmouth, North Dartmouth, Massachusetts.

Correspondence concerning this column should be addressed to Marianne Ryan, Associate University Librarian for User Service Strategies, Northwestern University, 1970 Campus Drive, Evanston, IL 60208; email:marianne-ryan@northwestern.edu.
In the introduction to their column, co-authors Emma Wood and Jessica Almeida aptly note that libraries and fines have long been synonymous. The notion of librarians as punitive avengers, be it for enforcing silence or demanding payback for overdue items, is commonly held and has been widely caricatured. The image is one that, more and more, many of us don't embody or wish to embrace. Against a backdrop of social theory, and with an emphasis on customer service and relationship building, Wood and Almeida present an appealing, practical alternative in the form of a fine-free framework. While not necessarily adaptable to all library environments, the model-along with its broader impacts-is well worth considering.-Editor

$\mathrm{H}$ ave you ever lent something to a friend with the expectation that they would return it promptly, only to find yourself in the role of repo man? Sometimes the best intentions give rise to counterintuitive behavior, responses that generally muddle the relationship. Such is the plight of libraries. Historically, this dilemma has been addressed by the institution of fines, but this solution is increasingly misaligned with the mission of service. The question of why we charge fines in the first place has already been asked, and the answer is resoundingly: penalty and revenue. ${ }^{1}$ The reality of uncertain or diminishing budgets may seem to favor late fees, but what of declining usage and the current instability of libraries? What of fee efficacy? What of the dwindling demand for print material?

UMass Dartmouth School of Law Library is a small library in Southeastern Massachusetts that does not attach monetary penalty to overdue materials. Even without the threat of hourly or daily fees, something compels students to turn in their books on time. The conscientiousness of these students may seem miraculous, particularly to those whose experiences, personal or professional, have been with fee-charging institutions. Explanation for this phenomenon can be found in social repercussions. ${ }^{2}$ In an environment where everyone is known by name, it is a simple process to determine who has kept a reserve textbook past time. No one wants to be known for monopolizing the Contracts text only hours before the midterm. It is also daunting for students to return a late book and make eye contact with the librarian whom they have come to know or will inevitably come to know over the course of their career at a small school. Despite all the privacy protections that librarians strive to preserve, anonymity is sometimes impossible.

Libraries have long been associated with the term "fine." The two are sadly synonymous. This is clear in the expressions 
of our patrons when they are first informed that we do not charge late fees. Their responses are typically relief or raisedeye-brow skepticism, and are often followed by emphatic offers to just pay anyway. Clearly fines have come to be accepted as a necessary evil by both patrons and librarians. ${ }^{3}$

The hard-dying fee policy of our profession may be hindering progress. Negative associations often take generations to correct. The episode of Seinfeld comes to mind where a library cop torments Jerry for a book that was not returned twenty years earlier. ${ }^{4}$ The image of a library relentlessly pursuing restitution decades beyond a due date is certainly unbecoming, but it's not too far-fetched. ${ }^{5}$ The stereotype of the unfriendly, tightly wound librarian may never fully dissipate, but we might be able to speed up the process by rejecting some of her legacy.

The purpose of this article is to explore what we consider the successes of a fine-free policy for a small academic library. This discussion is by no means a recommended model for libraries of all sizes and types. Rather, we hope that our experience, in part or in whole, may have merit for other librarians who are considering a departure from fines. Through this narrative, we consider the social implications of fines for both patrons and librarians. We intend to draw connections between service-forward policies and student sense of community. By considering the themes of social theory, we hope to elaborate on the factors that constitute an effective fine-free approach.

\section{APPLIED THEORY}

The deterrence hypothesis would suggest that tying a price tag to book tardiness should curb the unwanted behavior. It's simple enough. If one does not wish to pay a fee, he or she will strictly adhere to due dates. Crime continues despite prisons, and late library books still appear in return bins as the screeching tires of the getaway car are heard for miles. Those who have worked in public libraries know that often these books have apologetic notes pinned to their jackets. There is great significance in the apology notes and in the burned rubber. We regularly use the word "appear" for late books that have made a sudden return. The more overdue the book, the more likely it is to turn up in an outdoor bin or be slipped discretely onto the circulation desk while no one is looking. There is a certain Big Foot quality to the mysterious arrival of these overdue materials, and there is explicit shame in the delivery. That shame is a weightier theme of the late book dilemma than the money.

A study was conducted in a daycare center by imposing a fine on parents for picking up their children after 4 p.m. ${ }^{6}$ Over time, an increasing number of parents began to arrive late. They saw the fine as a price for additional care, and they felt no social debt for traipsing in past four o'clock. Before fines, parents felt obligation, possibly gratitude, to the caregiver who had to stay behind and tend to their children. They also wished to avoid any "uncertain" consequences by way of not having a contract of penalty. A structured fee schedule alleviates the unknowns. It's plausible that social stigma also kept them on schedule. After the fine structure was put into place, higher bills simply became a social norm, and the payment felt like compensation for the extended hours. This same justification works for library patrons. They knowingly keep books past their due date and throw up their hands to say "I'll just pay the fine." In a fine-less environment, a price to soothe the shame of being late does not exist.

Students who approach the main desk ready to fess up and hand over their money represent the fine-as-price theory. ${ }^{8}$ Juxtaposed to the book drop-and-run model, these guilt-conscious patrons want to pay up and be forgiven. Even after being informed that we do not charge fines, they often insist, pulling out their wallets to repeatedly ask "are you sure?" This is admittedly a highly satisfying exchange for a librarian. The exoneration is more feel-good than any John Hughes film you've ever seen. This is a heroic moment, and a guarantee for repeat patronage.

Reciprocity is the crux of our case for a successful finefree model. By virtue of being a small community, our library has an innate ability to impose social repercussion. In an article exploring the psychological relationship to incentive, the author states that "social approval means that we are the objects of others' admiration while disapproval means that we are the objects of others' disgust and contempt." In an overdue book scenario, a student could meet social disapproval from two sources: their peers and the librarians. Fehr concludes that "while social approval may be valued positively because it sometimes generates material benefits, we believe that most of us also value social approval positively (and disapproval negatively) for its own sake."10 Ultimately, even without fines in place, an effective dissuasive system exists in the form of social incentive. Free resources are exchanged for respect of policy and nothing more. This is not to say that a breach would lead to revocation of the use of those resources, but patrons choose not to betray social norms by disappointing their classmates and library staff. ${ }^{11}$

Kindness is also a critical motivator in a reciprocal relationship. As Fehr states, "refraining from the explicit threat of punishment may be perceived as kind."12 This concept relates to fines as an inescapable library theme. By simply not imposing fines, we as librarians appear kind and accommodating. Penalty is so pervasive in the traditional notion of libraries, that its absence is deemed merciful, even when it is merely policy. If we also outwardly exhibit the characteristics of kindness, students are more likely to reciprocate. A cooperative, friendly atmosphere is more likely to deter actions that would warrant social disapproval. This is the age-old "you scratch my back I'll scratch yours" idiom without all the negative financial connotations. Rather, we assert that backscratching just for the sake of being nice fosters the same sort of mutual consideration.

Michael Yeung explores the concept of reciprocity in libraries using trust games and concludes that trust can "provide a valid basis of explanation for many different 


\section{MANAGEMENT}

observed social phenomena, and this explanation, in turn, can be applied to the design of many public policies to yield a collective outcome that may improve the welfare of the society." 13 Yeung designed circulation games that incited "every man for himself" strategies as well as cooperation. ${ }^{14}$ Students with greater levels of trust have a tendency to follow loan policies out of consideration for their peers. Trust is an essential element of cooperation between strangers. The absence of fines is implied trust. In place of monetary penalty is the implication that the system will work based only on patron compliance, thus establishing that the library trusts its patrons. When students have established trust among themselves and librarians, the fine-free system thrives.

Libraries can strengthen trust in a community as a whole. ${ }^{15}$ The availability of library space and infrastructure "creates interaction[s] that users think are socially helpful and thereby generates social trust." ${ }^{.16}$ By providing space to collaborate, libraries encourage trust-building among community members. Similarly, trust is established through access. The goal of lending resources is to further social progress. This intent, unobscured by penalty, evokes trust because it is supportive of the collective.

\section{NUTS AND BOLTS}

By definition, the concept of "not" doing something is passive, but there are behind-the-scenes procedures in our inaction. We do not un-participate in fine collection by sitting on the sidelines; rather we actively waive balances and follow procedures when the rare occasion arises that a book is never coming back. Despite the apparent conscientiousness of our students, fines sometimes accrue when books are not promptly checked in by staff (i.e., a reserve item sits on the circulation desk for fifteen minutes while a staff member converses with a student) or due to genuine late return. The description to follow outlines the actions behind our fine exemption.

UMass Law Library serves approximately two hundred law students and fifty full time and adjunct faculty members as well as staff, public patrons, and the UMass Dartmouth community. As part of that community, we share access services functionality and modules with the main campus library. Alma, our Integrated Library System (ILS), applies the same policies to both populations. Although there is a marriage of rules within the Alma environment, the shared fine policy does not extend to practice.

The main campus library does charge late fees,$^{17}$ following a model that is typical for a large institution. This policy is well-suited to their population of nearly ten thousand, ${ }^{18}$ and the revenue has a positive impact on the library operations budget. Notices are overseen in the Alma system by the main campus library and delivered via email to patrons with overdue materials. These notices serve as due date reminders for law students and faculty, but the fees noted in these standardized emails can sometimes cause alarm. This can temporarily shift the friendly paradigm when a patron knows they returned an item and now expects to owe money. Often law students or faculty in receipt of these emails will contact the law library staff, and fees are manually waived by librarians. Although overdue balances are regularly discharged, books remain on patron accounts or are moved to a "missing book" account until they can be located. If a patron claims that he or she returned a book, librarians check the shelves. If the book isn't found, a librarian files a missing item form. Missing books undergo several searches until they are located, replaced, or removed from the system. For the past three years, we have logged missing or claimed returned items, and at present, only nine are still unresolved. In the last year, the library purchased approximately five books as replacement copies while we tracked 2,250 circulations for barcoded material.

Institutional holds are placed on graduating students who have outstanding library books. Just like a hold from the bursar's office for tuition owed, this prevents a diploma from being released. In the last three years, one student had such a hold placed that did not result in the quick return of the book. That book is still at large.

\section{LIMITATIONS AND CONSIDERATIONS}

Concern for our staff is a motivating factor in opting out of fine collection. As with most academic libraries, we are open late at night. Our law library is in a small building, three miles from main campus and subsequently from public safety. We are open to the community, and have one security guard that works a few nights a week. Security is always a concern. Having extra money breeds worry about theft, which can become a burden to staff. Fines are a responsibility that must be weighed against outcomes. If fines were to be adopted, librarians could define policies to enhance safety such as only collecting fines during the day or restricting public use, but rules such as these are a hindrance to access and threaten patron satisfaction by exclusion. Book delinquency is not a problem we are seeking to remedy, and although added revenue would be welcome, the probable strike to satisfaction would not be worth the equally probable low-dollar gain. Even for those libraries that take in a significant sum of money, the amount still tends to be small relative to overall budget.

The paucity of our staff dissuades us from exerting energy on processing fees. The law library staff are composed of four librarians, one staff assistant, and ten student circulation workers. Time saved by not collecting fines is allocated to developing programs, assisting with faculty research, and managing the day-to-day. Although we do devote time to waiving fees as described in the preceding section, fine collection would undoubtedly augment those duties to include interactions with patrons who owe money, making change, and transferring funds to the bursar. Collecting fines could ultimately add cost to our library through time spent establishing policies and pursuing debtors. Some libraries have turned to collection agencies to lessen their own workloads. ${ }^{19}$ 
"Problem patrons," or those with a tendency to make a scene, are well known to the library profession. Overdue fees are often a cause of disgruntlement. We have encountered our fair share of difficult situations, but by not collecting money, we reduce confrontation, and consequently librarian stress. This leads to greater job satisfaction for both librarians and student staff. By removing the debt factor or the threat of cutting off access to resources, we reduce uncomfortable exchanges. ${ }^{20}$ Instead, we can work in an environment where we make the needs of patrons a priority. This customer service strategy is measurable in the feedback we get from student surveys every year and the lengthy waitlist of students hoping to work in the library.

It should be noted that our fine-free policy is unadvertised. Aside from this article, we have not made a public statement about it. It is unknown whether this would influence return rates, but we suspect that our in-person communication about our policy may contribute to our sense of community. With library fines so implicit in our culture, their existence is assumed, so informing patrons that this isn't the case is relayed during a personal interaction. Students are appreciative that we waive fees, and most students work hard to return items on time. There are occasions when a student or two will take advantage of the system, but have found a way to compromise in these exceptional situations.

We are fortunate that this policy existed before we joined the library staff. We did not need to make our case to the administration to waive fees. The administration was on board from day one. The view that a fine-free library enables a better work environment for library staff and a better learning environment for our patrons is shared by all.

\section{CONCLUSION}

We are not the most altruistic librarians in the profession. We still want our books back. The fine-free approach works best for our population and staff because we rely on a positive model of service to stay viable. In 2000, Eastern Kentucky University Libraries went fine free and found that it increased student satisfaction. ${ }^{21}$ Our annual surveys indicate that students and faculty view the library favorably. We work hard to have good relationships with patrons, including knowing their names and their stories. One can see how a dispute over a book being an hour late and demanding a two-dollar fine can put a damper on a positive relationship. What if this two-dollar fee accrued each time they came into the library? Why would they want to come back?

Our recipe for an effective, really free library is one that is small in size, has a community-driven atmosphere, and upholds a strong service orientation. The mission of UMass Law is to provide an "excellent, affordable, and accessible legal education." 22 We assert that added library fees would be inconsistent with these tenets. Prevailing wisdom suggests that if we give an inch (by not punishing overdues), patrons will take a mile. However, it has been our experience that in giving an inch, students generally stay within bounds. At one time we might have envisioned post-apocalyptic chaos in a fine-free environment, with patrons looting the shelves with no intention of bringing their books back. Instead, we have found that they respond in kind to what they perceive as trust and kindness. Fine exemption also relieves librarians of the undesirable duty of fine collection, and allows our professional focus to be on service-oriented activities. Our policy allows a sigh of relief on both sides of the desk. It is our nod to Open Access, and a display of empathy toward student debt. When we are no longer disciplinary, we can only be called helpful, the holy grail of compliments in the library profession.

\section{References}

1. Daniel Sifton, "The Last Taboo: Abolishing Library Fines," Canadian Journal of Library and Information Practice and Research 4, no. 1 (2009): 2.

2. Uri Gneezy and Aldo Rustichini, "A Fine Is a Price," Journal of Legal Studies 29, no. 1 (January 2000): 13, http://rady.ucsd.edu /faculty/directory/gneezy/pub/docs/fine.pdf.

3. Chelsea Woods, "Don't End Library Fines," Baltimore PostExaminer, August 26, 2012, http://baltimorepostexaminer.com /dont-end-library-fines/2012/08/26.

4. Jerry Seinfeld and Larry David, writers, "The Library," Seinfeld (Shapiro/West Productions, Castle Rock Entertainment, 1991).

5. Anne Barnard and Jo Craven McGinty, "How One Overdue Book Can Hurt a Credit Record," New York Times, December 26, 2007, www.nytimes.com/2007/12/26/nyregion/26debate.html?_r=0.

6. Gneezy and Rustichini, "A Fine Is a Price," 4-5.

7. Michael Yeung, "Library Fines, Trust Games and Reciprocity," Reinvention 3, no. 1 (2010), http://www2.warwick.ac.uk/fac /cross_fac/iatl/reinvention/issues/volume3issuel/yeung.

8. Gneezy and Rustichini, "A Fine Is a Price," 14.

9. Ernst Fehr and Armin Falk, "Psychological Foundations of Incentives," European Economic Review 46, no. 4-5 (2002): 705, https://doi.org/10.1016/s0014-2921(01)00208-2.

10. Fehr and Falk, "Psychological Foundations of Incentives," 705.

11. Tim Kurz, William E. Thomas, and Miguel A. Fonseca, "A Fine Is a More Effective Financial Deterrent When Framed Retributively and Extracted Publicly," Journal of Experimental Social Psychology 54 (2014): 171, https://doi.org/10.1016/j.jesp.2014.04.015.

12. Ibid.

13. Yeung, "Library Fines, Trust Games and Reciprocity."

14. Ibid.

15. Andreas Varheim, Sven Steinmo, and Eisaku Ide, "Do Libraries Matter? Public Libraries and the Creation of Social Capital," Journal of Documentation 64, no. 6 (2008): 877.

16. Ibid.

17. "Borrowing Policy," UMass Dartmouth, Claire T. Carney Library, accessed November 16,2016, www.lib.umassd.edu/about/policies /borrowing-policy.

18. "Campus Profile," UMass Dartmouth, accessed November 22, 2016, www.umassd.edu/about/.

19. Nanci Milonel Hill, "Are Collection Agencies the Answer?" Public Libraries (November/December 2006): 18, www.ala.org/pla/sites /ala.org.pla/files/content/publications/publiclibraries/pastissues /novdec2006pl.pdf.

20. Gregory A Mitchell, "Fineless Circulation at EKU Libraries: An Evaluation," Kentucky Libraries 64 (2000): 18.

21. Ibid.

22. "Mission," UMass Law, accessed November 22, 2016, http:// www.umassd.edu/law/about/mission/. 